УДК 338

$10.17213 / 2075-2067-2019-4-107-116$

\title{
ОСОБЕННОСТИ И КОНКУРЕНТНЫЕ ПРЕИМУЩЕСТВА БЕСКОНТАКТНЫХ МОБИЛЬНЫХ ПЛАТЕЖНЫХ СИСТЕМ: ПРЕДПОСЫЛКИ РАЗВИТИЯ, ПРОБЛЕМЫ И РИСКИ МОШЕННИЧЕСТВА НА РОССИЙСКОМ РЫНКЕ
}

\author{
(C) 2019 г. Л. В. Голощцапова *, Л. А. Иванова**, В. В. Локтионов**, А. С. Глазунов** \\ *Российский экономический университет им. Г. В. Плеханова, г. Москва \\ **Курский государственный университет
}

Целью исследования является анализ работы мобильных платежных систем Apple Pay, Samsung Pay, Google Pay и Garmin Pay, особенностей и конкурентных преимуществ каждой из них, а также предпосылок дальнейшего развития на российском рынке, выявление проблем и рисков мошенничества в ходе пользования мобильными приложениями. В процессе написания были использованы: метод контент-анализа, анализа документов и наблюдений, а также методы стратегического анализа. Результаты исследования: в статье раскрывается механизм работы мобильных платежных систем, особенности и конкурентные преимущества каждой из них, а также предпосылки дальнейтего развития на российском рынке, отмечаются проблемы и риски мошенничества в ходе пользования мобильными приложениями, анализируется время прихода международных систем в регион. Практическая значимость: выделенные в процессе исследования особенности первичной реализачии и дальнейшего развития систем бесконтактных мобильных платежей и их учет может помочь при совершенствовании национальной платежной системы «Мир» и пользователям, впервые сталкивающимся с разнообразием сервисов.

Ключевые слова: бесконтактная оплата; конкурентные преимущества; платежные системы; мобильные платежные системы; NFC; смартфоныл.

The purpose of the study is to analyze the operation of Apple Pay, Samsung Pay, Google Pay and Garmin Pay mobile payment systems, the features and competitive advantages of each of them, as well as the prerequisites for further development in the Russian market, identifying problems and risks of fraud while using mobile applications. In the process of writing were used: the method of content analysis, analysis of documents and observations, as well as methods of strategic analysis. The results of the study: the article reveals the mechanism of mobile payment systems, the features and competitive advantages of each of them, as well as the prerequisites for further development in the Russian market, highlights the problems and risks of fraud in the use of mobile applications, analyzes the time of arrival of international systems in the region. Practical significance: the features of the primary implementation and further development of contactless mobile payment systems highlighted in the research process and their accounting can help with the improvement of the national payment system "Mir» and users who are confronted for the first time with a variety of services.

Key words: contactless payment; payment systems; mobile payment systems; NFC; smartphones. 
Зарубежные исследователи отмечают, что мобильные платежи - это не просто новая мера повышения эффективности существующих сетей. Внедрение мобильных платежей обусловлено чем-то помимо стимулирования доли рынка посредством повышения уровня удобства пользования для конечного потребителя. Стремление к мобильным транзакциям может восприниматься как часть более глубокой логики цифровой экономики: создание требуемого уровня пользовательского опыта для закрепления тесной связи между онлайн-брендами и повседневной жизнью потребителей. Была утверждена и воплощена в жизнь новая роль для смартфона как для финансового устройства, поощряющего поднятие пользовательского опыта людей с открытыми банковскими счетами на новый уровень по части платежей [21].

Соберем воедино все существующие в России бесконтактные мобильные платежные системы и разберемся в их особенностях (см. табл. 1).
Отличительной особенностью Samsung Рау является поддержка способа оплаты с помощью MST-технологии, которая использует электромагнитное поле, чтобы заставить терминал без поддержки бесконтактных платежей думать, что по нему была проведена настоящая карта. Благодаря этому поддерживается не менее 90\% всех терминалов, исключения составляют терминалы, требующие физического размещения карты внутри себя. В том же году Samsung анонсировал Pay Mini - приложение с поддержкой телефонов на Android без NFC (не только своей марки), предназначенное только для онлайн-платежей. В июне 2017 года сервис был запущен, но до России так и не добрался; также не удалось реализовать планы по выходу на конкурирующей платформе Apple iOS. Владельцы аппаратов Samsung c NFC не ограничены собственным сервисом компании, как и потребители других смартфонов на Android они могут также использовать систему Google Pay.

\section{Сравнительная характеристика бесконтактных мобильных платежных систем в России в порядке появления на рынке ${ }^{1}$}

\begin{tabular}{|c|c|c|c|c|c|c|}
\hline Пункты & $\begin{array}{l}\text { Samsung } \\
\text { Pay }\end{array}$ & $\begin{array}{l}\text { Apple } \\
\text { Pay }\end{array}$ & $\begin{array}{c}\text { Google } \\
\text { Pay }\end{array}$ & Alipay & $\begin{array}{l}\text { Garmin } \\
\text { Pay }\end{array}$ & WeChat Pay \\
\hline $\begin{array}{c}\text { Дата выхода } \\
\text { в РФ }\end{array}$ & $9 / 29 / 2016$ & $10 / 4 / 2016$ & $5 / 23 / 2017$ & $7 / 14 / 2017$ & $12 / 19 / 2017$ & 7/9/2018 \\
\hline $\begin{array}{l}\text { Число подде- } \\
\text { рживаемых } \\
\text { банков в России }\end{array}$ & 48 & 62 & 74 & $\begin{array}{c}\text { Точное } \\
\text { число не } \\
\text { уточняется }\end{array}$ & 27 & $\begin{array}{c}\text { Точное } \\
\text { число не } \\
\text { уточняется }\end{array}$ \\
\hline Типы устройств & $\begin{array}{l}\text { Умные } \\
\text { смартс }\end{array}$ & $\begin{array}{l}\text { часы; } \\
\text { роны }\end{array}$ & & 3ce & $\begin{array}{c}\text { Умные } \\
\text { часы }\end{array}$ & Bce \\
\hline Совместимость & $\begin{array}{l}\text { Samsung } \\
\text { на Android }\end{array}$ & iOS & $\begin{array}{c}\text { Android } \\
5.0+\end{array}$ & $\begin{array}{l}\text { Только для } \\
\text { туристов } \\
\text { из Китая }\end{array}$ & $\begin{array}{c}\text { iOS, } \\
\text { Android }\end{array}$ & $\begin{array}{c}\text { Только для } \\
\text { туристов } \\
\text { из Китая }\end{array}$ \\
\hline $\begin{array}{l}\text { Принцип } \\
\text { работы }\end{array}$ & $\begin{array}{l}\mathrm{NFC+} \\
\mathrm{MST}\end{array}$ & \multicolumn{2}{|c|}{ NFC } & $\begin{array}{c}\text { Считывание } \\
\text { QR-кодов }\end{array}$ & NFC & $\begin{array}{c}\text { Считывание } \\
\text { QR-кодов }\end{array}$ \\
\hline $\begin{array}{l}\text { Дешевый } \\
\text { смартфон }\end{array}$ & $\begin{array}{c}\text { Galaxy J5 } \\
\text { (2017): } \\
12990 \text { P }\end{array}$ & $\begin{array}{l}\text { iPhone } \\
\text { SE: } \\
18490 \text { P }\end{array}$ & $\begin{array}{l}\text { BQ 5001L } \\
\text { Contact: } \\
5490 \text { P }\end{array}$ & - & - & - \\
\hline
\end{tabular}

1 По данным с ресурсов (Samsung RU; Apple; Google; Garmin Russia). 
Apple использует при оплате с iPhone в качестве подтверждения платежа Touch ID (дактилоскопический датчик) и Face ID, начиная с iPhone $\mathrm{X}$. Так же, как и Samsung с носимыми устройствами, компания позволяет совершать бесконтактные платежи со своих Apple Watch, для оплаты требуется только двойное нажатие по ним. На смартфонах без NFC оплата c Apple Pay может также проходить с помощью умных часов. Платежный сервис, согласно источникам «Ведомостей», берет комиссию с банков за каждую транзакцию в размере $0,05 \%$ от суммы покупки по дебетовым и 0,12\% по кредитным картам, «кроме того, банк должен платить 45 Р в год за каждую карту, подключенную к сервису», однако точно известно, что ни с Samsung Pay, ни c Apple Рау пользователи сами не выплачивают никакую комиссию.

Поисковой гигант Google, несмотря на игнорирование российского рынка для импорта своих аппаратных продуктов (смартфоны Pixel, устройства для умного дома и т.д.), все активнее предоставляет поддержку в России сервисов, ранее работающих только в США и ограниченном числе других стран - этим летом стали доступны Google Ассистент на русском языке и Google Lens (Объектив). Благодаря отсутствию привязки к собственным аппаратам, платежная платформа доступна на внушительном количестве устройств с NFC на базе Android [16]. В феврале 2018 года корпорация завершила процесс объединения Android Pay и Google Wallet под брендом Google Play. Для конечного пользователя такое переосмысление означает только более глубокое встраивание системы в приложения на смартфоне.

Остальные платежные системы, упоминаемые в таблице, можно относить к разряду нишевых. К преимуществам китайских Alipay и WeChat Pay можно отнести меньшую зависимость от аппаратной начинки за счет использования технологий оплаты через сканирование QR-кода, выводимого смартфоном, налаженную интернациональную платформу (WeChat Рау основан на мессенджере WeChat). Главная проблема обоих систем в невозможности работы для самих россиян - по ней могут расплачиваться только граждане Китая. Партнеры объясняют это ориентацией на китайских туристов и граж-

Таблица 2

\section{Сравнительная характеристика основных бесконтактных мобильных платежных систем в России в порядке первого запуска в мире ${ }^{2}$}

\begin{tabular}{|c|c|c|c|c|c|c|}
\hline \multicolumn{2}{|c|}{ Первый запуск (\#1 в списке) } & \multicolumn{3}{|c|}{ Первая страна в Европе } & \multicolumn{2}{|c|}{ Запуск в России } \\
\hline Страна & $\begin{array}{c}\text { Дата } \\
\text { выхода }\end{array}$ & Страна & $\begin{array}{c}\text { Дата } \\
\text { выхода }\end{array}$ & В списке & $\begin{array}{c}\text { Дата } \\
\text { выхода }\end{array}$ & В списке \\
\hline \multicolumn{7}{|c|}{ Apple Pay } \\
\hline $\begin{array}{c}\text { Соединенные } \\
\text { Штаты }\end{array}$ & $10 / 20 / 2014$ & Великобритания & $7 / 14 / 2015$ & $\# 2$ & $10 / 4 / 2016$ & $\# 10$ \\
\hline \multicolumn{7}{|c|}{ Samsung Pay } \\
\hline Южная Корея & $8 / 20 / 2015$ & Испания & $6 / 2 / 2016$ & $\# 4$ & $9 / 29 / 2016$ & $\# 8$ \\
\hline \multicolumn{7}{|c|}{ Google (Android) Pay } \\
\hline $\begin{array}{c}\text { Соединенные } \\
\text { Штаты }\end{array}$ & $9 / 11 / 2015$ & Великобритания & $5 / 18 / 2016$ & $\# 2$ & $5 / 23 / 2017$ & $\# 11$ \\
\hline \multicolumn{7}{|c|}{ Garmin Pay } \\
\hline $\begin{array}{c}\text { Соединенные } \\
\text { Штаты }\end{array}$ & $8 / 31 / 2017$ & Швейцария & $12 / 6 / 2017$ & $\# 3$ & $12 / 19 / 2017$ & $\# 4$ \\
\hline
\end{tabular}

2 Составлено авторами по предоставленным компаниями датам запуска платежных систем в соответствующих странах. 
дан КНР, проживающих в России, работоспособность обеспечена в ограниченном числе точек оплаты - крупные торговые точки «люкс-класса»: ЦУМ, ГУМ и другие универмаги с кассовой программой POSX. Наряду с этим российскими представительствами заявлено отсутствие в настоящий момент планов по открытию сервиса россиянам.

Рассмотрим, насколько долго вышеперечисленные платежные системы приходили в Россию (см. табл. 2).

Как можем наблюдать, Samsung Pay и Google (Android) Рау были представлены практически в одно время, но Samsung выпустила свою систему на российский рынок многим раньше; a Garmin Рау стала единственным сервисом, запущенным в России в том же году, что и на родине производителя. К тому же Россия стала второй страной в Европе, чьи карты начали поддерживаться Garmin Pay, разрыв в датах выхода с Австралией и Швейцарией минимален. Положительным моментом в долгом выходе систем в России можно назвать сложившийся в ходе запуска в других странах опыт взаимодействия с банками, который позволил Apple и Samsung уже в первые месяцы запуска платформы на нашем рынке договориться с внушительным списком банков.

Антирейтинг возглавляет Apple, которая запускала свою платежную систему в России в 2,68 раза дольше, чем в самой первой евро- пейской стране. Такая задержка проявляется и в доступности некоторых других сервисов купертиновской компании: умный ассистент Siri на русском языке (1069 дней против 801 в случае с аналогом от Google, при этом в Siri для России функционирует только 1/3 заявленных возможностей клиента [26]); приложение Apple TV (до сих пор не запущено) и пр. При этом российские продажи продукции Apple показывают, что для рядового покупателя это не является решающим фактором в выборе смартфона. По данным Telecom Daily, за ноябрь 2017 г. Apple заняла долю в 43,1\% российского рынка смартфонов в денежном выражении (первое место), что является рекордным показателем для iPhone в России за период с 2010 года) [1].

Samsung из того же источника занимает уже второе место в денежном выражении с долей в $25 \%$. На рисунке видно, что из трех крупных платформ система Samsung Pay добиралась до России быстрее конкурентов, при этом Samsung на текущий момент остается единственной компанией родом не из США, уверенно запустившей бесконтактный сервис в российском регионе.

На первый взгляд, из сопоставления числа поддерживаемых банков и количества дней до запуска в России напрашивается прямая связь между этими двумя показателями, однако существуют ограничения, которые отвергают возможность построения линейной регрессии:

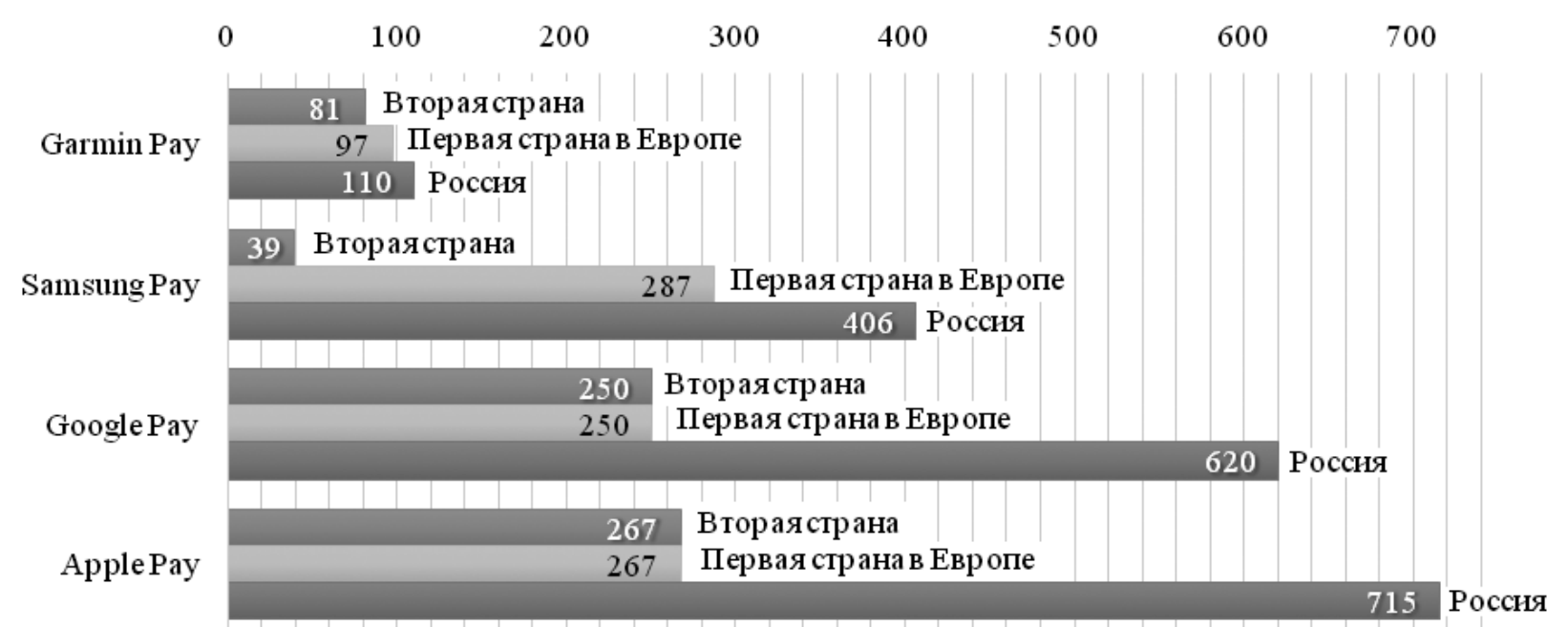

Рис. 1. Временные промежутки с момента выхода технологии в родной стране компании и до ее открытия в остальных странах, в днях ${ }^{3}$

3 Составлено авторами на основе данных из табл. 2. 
1) некорректность сравнения текущего числа банков с количеством дней до запуска в России, поскольку последняя величина остается постоянной;

2) первое взаимодействие с банками Google начала еще в 2011 году с запуском в США приложения Google Wallet, что и косвенно объясняет числовое преимущество перед остальными платежными системами, и исключает систему из выборки для регрессии;

3) параметров (коэффициентов) регрессии - 3-4 системы - слишком мало по отношению к числу факторов (2 ед.), что приводит к высокой стандартной ошибке регрессии и отрицанию любых связей;

4) количество поддерживаемых банков - спорная величина при прямом сравнении систем за счет неполноты поддержки всех карт в пределах банка; даже в пределах одной системы MasterCard или VISA наблюдается частичная поддержка выпущенных карт. Только Google предоставляет наиболее подробную информацию о видах поддерживаемых карт, когда другие системы указывают только или общие названия без конкретизации работающих видов карт, или названия банков;

5) улучшение текущих и обеспечение новых платежных инструментов происходит достаточно динамично по всему миру, однако нормативное и законодательное регулирование работы систем оплаты часто отстает от внедрения технических и организационных улучшений. Отечественные компании в целях стимулирования потребителей прорабатывают льготы по платежам, повышенный кэшбэк, акции с мобильными бесконтактными платежами [13].

Например, в августе российская компания Яндекс заявила о добавлении в сервис Яндекс.Такси возможности оплаты поездок через платежную систему Google Pay. Приложение не просто получило расширение методов расчета, а еще снизило пользователям на 100 Р стоимость каждой из первых 10 поездок, оплаченных через эту систему. Из условий времени действия акции (до конца текущего года) следует, что Яндекс заинтересован в продолжительном росте транзакций, осуществляемых смартфонами. Это утверждение подтверждается тем, что сервис Яндекс. Деньги, по данным исследовательской компа- нии Mediascope, на момент 2017 года являлся «самой популярной и самой известной системой электронных денег в России»: 24,7\% россиян в возрасте от 18 до 55 лет минимум раз в год расплачивалась Яндекс.Деньгами со своих смартфонов [5]. Ранее в 2017 году подобные временные акции проводили Аэроэкспресс и Burger King, предоставлявшие $50 \%$ скидку на билеты и фаст-фуд соответственно. Банки также не остаются в стороне: в июле этого года Совкомбанк объявил, что вводит повышенный в 3-4 раза кэшбэк за покупки, совершенные с помощью бесконтактной оплаты со смартфонов или умных часов в системах Apple Pay, Google Pay и Samsung Pay [4].

В начале 2018 года китайская компания-производитель телекоммуникационного и сетевого оборудования Huawei сообщила о выходе на международный рынок своей платежной системы Huawei Pay, действующей с 2016 года только на территории Китая. Планируется сделать Россию первым рынком за пределами Китая, поддерживающим сервис [5]. Несмотря на значимость заявления в масштабах страны, для российских граждан такая услуга не сможет пользоваться большим спросом из-за работы приложения исключительно с банковскими картами China UnionPay, которые выпускаются узким кругом банков и не популярны среди россиян.

Также следует упомянуть отдельные приложения, в которых функция бесконтактной оплаты не являлась основным функционалом и была добавлена позднее.

1. Собственные приложения банков или сервисов электронных платежей. К таким, например, относятся приложение «Тинькофф» одноименного банка и «Яндекс.Деньги - платежи онлайн» от компании Яндекс. Они оба выступают в роли «мобильного банка», отличающей от универсальных бесконтактных мобильных платежных систем возможностью является показ остатка средств на карте. При авторизации в системе Яндекс.Деньги и заходе в пункт «Бесконтактные платежи» приложение автоматически создаст виртуальную карту, по которой и будет происходить бесконтактная оплата в магазинах, а деньги спишутся со счета сервиса. Дополнительно предоставляется возможность привязки внесистемных карт: Visa (включая 
Electron), MasterCard, Maestro и Мир - аналогично без отображения баланса

2. Приложения-виртуальные кошельки. К таким относится приложение «Кошелек. Скидочные и бонусные карты» от разработчика CardsMobile. Изначальным и основным функционалом сервиса выступает хранение фотографических оттисков скидочных и подарочных карт различных российских магазинов и генерация штрих-кода, который действует на кассе и таким образом избавляет от необходимости ношения с собой десятка пластиковых дисконтных карт. В 2015 году в приложение была внедрена бесконтактная технология MasterCard, что и позволяло осуществлять бесконтактные платежи на сотни моделей поддерживаемых смартфонов. Очевидным недостатком решения является отсутствие поддержки других карт (Visa или «Мир») и небольшое число поддерживаемых банков («МТС-банк», «Русский стандарт», «Санкт-Петербург», «Московский индустриальный банк»).

Весной национальная платежная система «Мир» заявила о работе над созданием собственного бесконтактного платежного сервиса Мир Рау, выход намечен на осень [12]. Отметим, что на октябрь 2018 года карты «Мир» не поддерживаются системами Google Pay и Apple Pay, и, начиная с декабря 2017 года, Samsung Рау является единственным существующим вариантом их использования при мобильных бесконтактных платежах. Генеральный директор оператора платежной системы «Мир» Владимир Комплев рассматривает различные варианты реализации сервиса. Один из них заключается в использовании клиентами SIM-карт с технологией Bluetooth, «которая позволяет реализовывать взаимодействие снаружи телефона». По словам Комплева, это единственный возможный сейчас способ реализации бесконтактных платежей на платформе Apple. Проблему с принудительным переводом бюджетников на платежную систему «Мир», часть из которых теперь полученную зарплату сразу переводят на карты Visa/ MasterCard или обналичивают, председатель правления объясняет устоявшимися привычками и барьерами в головах людей [3].

Меж тем, в текущем виде «Мир» обладает заметными недостатками: реализация не во всех российских онлайн-магазинах, не- большой список стран функционирования, невозможность совершения покупок за границей без совмещенной кобейджинговой карты (с двумя платежными системами) МирMaestro, Мир-JСВ и Мир-UnionPay, которые выпускают ряд российских банков, а также отсутствие части услуг, ставших базовыми в банках с картами Visa и MasterCard. Также отдельно выделяют «не до конца разработанный механизм программы лояльности для пользователей карт»: создаются определенные трудности ввиду того, что участников, начисляющих проценты по кэшбэку в рамках разработок уникальной программы лояльности, не так и много [10].

Другая ситуация связана с тем, что платежные системы Visa и MasterCard давно обладают поддержкой протокола 3-D Secure, обеспечивающем дополнительную защиту при онлайн-транзакциях и возможность оспаривании операции банком-эмитентом и возврата средств держателю карты, протокол поддерживается многими сайтами с оплатой онлайн. Карты «Мир» в качестве временной меры были запущены с системой безопасности платежей MirAccept 1.0, основанной на решении 3-D Secure oт Visa, a c 1 августа 2017 года платежная система добавила новую платформу безопасности электронной торговли - MirAccept 2.0, уже основанную на спецификации Международной ассоциации по стандартам в области электронных платежных технологий EMVCo, причем раньше, чем аналогичные платформы были представлены на рынке системами MasterCard и Visa. Платформа добавляет удобства для российских пользователей, поскольку позволяет оплачивать услуги не только через браузеры, но и через мобильные приложения, а идентификация клиента может быть осуществлена и без ввода пароля из SMS, по биометрическим данным [14]. Остается открытым лишь вопрос скорости внедрения онлайн-магазинами поддержки этого сервиса в ходе оплаты товаров и услуг.

В мире логичным этапом развития бесконтактных платежей видится внедрение подхода к аутентификации, предполагающего использование биометрических параметров для полного устранения зависимости от наличных денег, пластиковых карт и гаджетов. Вместо этого оплата будет произво- 
диться посредством сканеров, считывающих вены на пальцах пользователя. Вероятность совпадения расположения вен у двух человек составляет 1 к 3,4 миллиардам, что делает этот способ оплаты очень безопасным. После привязки своей биометрии к банковской карте потребители смогут расплачиваться где угодно посредством бесконтактного сканирования [20]. Такой метод считается относительно новым, в настоящее время васкулярное сканирование широко распространено в Японии в банковской сфере и в медицинских учреждениях. К преимуществам технологии также относят невозможность обмана посредством муляжной руки (датчики реагируют на ток крови), стоимость таких сканеров значительно дешевле устройств чтения радужной оболочки глаза - другому рассматриваемому в других странах способу подтверждения личности картодержателя.

Новшества, вводимые Huawei с прицелом на китайский рынок, могут быть полезны для освоения системой «Мир». Так, в июле компания сообщила о выпуске NFC-меток с технологией One Touch. Ее принцип заключается в способности производить оплату с телефона на эти метки, от пользователя требуется только ввести нужную сумму и подтвердить платеж любым из способов аутентификации. Такая технология должна существенно снизить финансовую нагрузку с продавцов товаров и услуг, ведь им не придется приобретать POS-терминалы и сканеры QR-кодов [6].

Россия продемонстрировала, что готова к внедрению инновационных технологий на своем рынке. Это доказывает работоспособность сразу 4 из 5 мобильных бесконтактных систем, действующих в пределах и для жителей нескольких стран. Пятой считается система Fitbit Pay (от американской компании Fitbit, специализирующейся на производстве носимой электроники для фитнеса), которая функционирует в 17 странах, в том числе 10 из европейского региона; но в настоящее время она не имеет своего представительства на территории России, что и объясняет отсутствие сервиса. Мобильные устройства в этом десятилетии служат своеобразным двигателем технического прогресса и сейчас вызывают больший интерес и привлекательность для рядового потребителя, чем любая иная электроника на рынке с представляемы- ми в ней инновациями. Несмотря на обширный функционал, предоставляемый модулями NFC еще с 2010 года, в России смартфоны с этими модулями стали все чаще приобретаться в разрезе всех продаваемых ритейлерами смартфонов именно на фоне выхода бесконтактных мобильных систем, которые динамично развиваются и сокращают число привычных пользователю действий при осуществлении покупок. Перенятие опыта зарубежных компаний в реализации мобильных расчетов может помочь при разработке и улучшении национальной платежной системы «Мир». Сервисы не стоят на месте, и поэтому российские пользователи получают все больший список поддерживаемых банков и приложений, которые они могут использовать в повседневных транзакциях.

\section{Литература}

1. В России бум продаж смартфонов, поддерживающих бесконтактные платежи // Валерий Кодачигов, Ведомости. [Электронный ресурс] - Режим доступа: https://www.vedomosti. ru/technology/articles/2018/01/29/749217-bumprodazh. (Дата обращения: 07.10.2018 г.).

2. В России появится платежный сервис «Мир Рау» // Банки.ру. [Электронный ресурс] — Режим доступа: http://www.banki.ru/ news/lenta/?id=10384565. (Дата обращения: 07.10.2018 г.).

3. Владельцы карты рассрочки «Халва» получат $12 \%$ кэшбек с покупок смартфоном // Совкомбанк. [Электронный ресурс] Режим доступа: https://sovcombank.ru/about/ news/vladeltsy karty rassrochki khalva poluchat_12_keshbek_s_pokupok_smartfonom/. (Дата обращения: 07.10.2018 г.).

4. Исследование Mediascope: пользователи предпочитают платить через приложения // Яндекс. [Электронный ресурс] - Режим доступа: https://money.yandex.ru/page?id=529142. (Дата обращения: 07.10.2018 г.).

5. Платежный сервис Huawei Pay был улучшен при помощи технологии One Touch // iXBT.com. [Электронный ресурс] Режим доступа: https://www.ixbt.com/ news/2018/07/03/huawei-pay-one-touch.html. (Дата обращения: 07.10.2018 г.).

6. Платить за поездки теперь можно через Google Pay // Яндекс. [Электрон- 
ный ресурс] - Режим доступа: https://taxi. yandex.ru/blog/google-pay. (Дата обращения: 07.10.2018 г.).

7. Россия - Справка - Google Рay// Google. [Электронный pecypc] — Peжим доступа: https://support.google.com/ pay/answer/7397640. (Дата обращения: 07.10.2018 г.).

8. Россия стала лидером по количеству привязанных карт в Android Pay // Анна Еpeмина, Ведомости. [Электронный ресурс] Режим доступа: https://www.vedomosti.ru/ finance/articles/2017/12/02/743932-rossiyaandroid-pay. (Дата обращения: 07.10.2018 г.).

9. Сериков B. B. Национальная платежная система «Мир». Ее сравнительный анализ с международными платежными системами Visa и Mastercard // Научные механизмы решения проблем. - 2017. - С. 119-123.

10. Силаева А.А., Игнатенков Г. К. Apple, Samsung и Android Pay: особенности бесконтактных мобильных платежных систем и перспективы их внедрения в России // Сервис в России и за рубежом. - 2017. T. 11. - Вып. 3. - С. 126-135.

11. Система «Мир Рау» появится осенью // РИА Новости. [Электронный ресурс] - Режим доступа: https://ria.ru/ economy/20180425/1519372480.html. (Дата обращения: 07.10.2018 г.).

12. Соколов Б.И., Мищенко С.В. Роль платежных систем в обеспечении устойчивого развития национальной экономики // Проблемы современной экономики. - 2015. №. 2 (54).

13. Сурина И.В., Мельникова М. С. Система платежных карт «Мир» как элемент национальной платежной системы // Вектор экономики. - 2017. - №. 11.

14. Технология NFC в смартфонах и ее практическое использование // Кирилл Кочетков, iXBT.com. [Электронный pe- сурс] - Режим доступа: https://www.ixbt. com/mobile/nfc-2013.shtml. (Дата обращения: 07.10.2018 г.).

15. Apple Рау берет с банков небольшую комиссию за каждую транзакцию // Анна Еремина, Ведомости. [Электронный ресурс] Режим доступа: https://www.vedomosti.ru/ finance/articles/2016/10/07/659962-apple-paykomissiyu. (Дата обращения: 07.10.2018 г.).

16. Garmin Pay - платежный сервис, c поддержкой технологии бесконтактных платежей // Garmin Russia. [Электронный ресурс] - Режим доступа: http://support.garmin. $\mathrm{ru} /$ support/solutions/articles/26000025030-Чтотакое-сервис-технология-garmin-pay-Какиеустройства-поддерживаются. (Дата обращения: 07.10.2018 г.).

17. HUAWEI и UnionPay International выводят систему HUAWEI Рау на международный рынок // HUAWEI. [Электронный pecypc] — Режим доступа: https://consumer. huawei.com/ru/press/news/2018/press_release huawei_pay/. (Дата обращения: 07.10.2018 г.).

18. IOS - Доступность функций iOS // Apple Россия. [Электронный ресурс] - Peжим доступа: https://www.apple.com/ru/ios/ feature-availability/\#siri. (Дата обращения: 07.10.2018 г.).

19. Ding G.H., Liu S., Holm O.E. A Study of Mobile Payment Behaviour for Different Countries // International Journal of Business and Information. - 2018. - P. 349-384.

20. Kremers R., Brassett J. Mobile Payments, Social Money: Everyday Politics of the Consumer Subject // New Political Economy. 2017. - V. 22. — №6. - P. 645-660.

21. Макеева Е.И., Довлатян Г.П. Особенности развития промышленности в условиях глобализации экономики // Современные исследования социальных проблем (электронный научный журнал). — 2015. №1. - C. 437-446. 


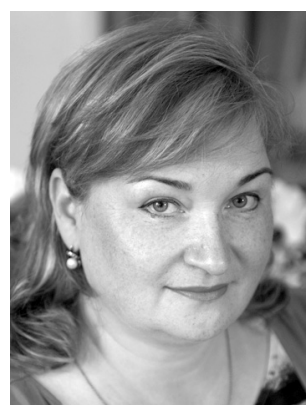

Голощапова Людмила Вячеславовна - кандидат экономических наук, доцент базовой кафедры финансового контроля, анализа и аудита Главного контрольного управления города Москвы Российского экономического университета им. Г.В. Плеханова.

Goloshchapova Liudmila Vyacheslavovna - candidate of economic Sciences, associate professor of the base Department financial control, analysis and audit Main control Department of the city of Moscow of Russian University of Economics named after G. V. Plekhanov.

117997, г. Москва, Стремянный пер., 36

36 Stremyanny ln., 117997, Moscow, Russia

Тел.: +7 (926) 883-37-73; e-mail: cool.lvg2012@yandex.ru

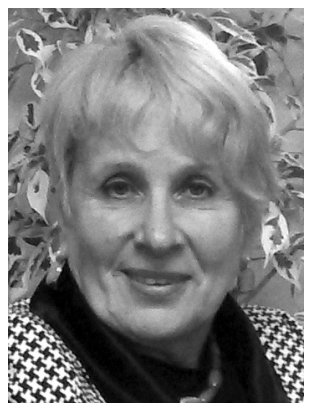

Иванова Людмила Анатольевна - кандидат экономических наук, доцент кафедры экономики Курского государственного университета.

Ivanova Lyudmila Anatolyevna - candidate of economic Sciences, associate Professor of the Department of Economics of Kursk state University.

305000 , г. Курск, ул. Радищева, 29, ауд. 421

29 Radischeva st., of. 421, 305000, Kursk, Russia

Тел.: +7(905) 041-79-73, e-mail: ivaviser@yandex.ru

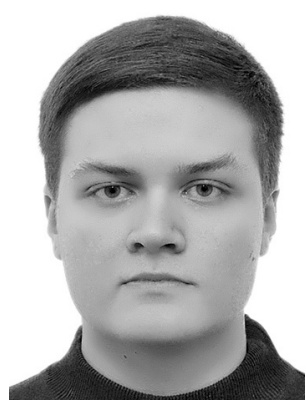

Локтионов Владислав Владимирович - магистрант экономического факультета Института экономики и управления Курского государственного университета.

Loktionov Vladislav Vladimirovich - master's student of the faculty of Economics of the Institute of Economics and management of Kursk state University.

305000, г. Курск, ул. Радищева, 29, ауд. 421

29 Radischeva st., of. 421, 305000, Kursk, Russia

Тел.: +7(905) 041-79-73, e-mail: vladhabit@ya.ru 


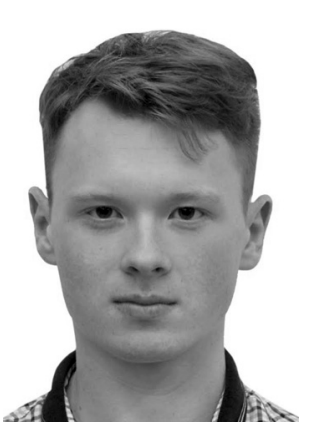

Глазунов Андрей Сергеевич - магистрант экономического факультета Института экономики и управления Курского государственного университета.

Glazunov Andrey Sergeevich - master's student of the faculty of Economics of the Institute of Economics and management of Kursk state University.

305000, г. Курск, ул. Радищева, 29, ауд. 421

29 Radischeva st., of. 421, 305000, Kursk, Russia

Тел.: +7(905) 041-79-73, e-mail: andreihabit@ya.ru 